\title{
O PERIÓDICO MOVIMENTO DA UNE (1962-1963): UM CANAL DO PENSAMENTO PROGRESSISTA
}

\author{
Carla Michele Ramos Torres ${ }^{1}$ \\ Maria Isabel Moura Nascimento²
}

\begin{abstract}
RESUMO: Este artigo se situa no campo da história da educação brasileira e tem como objeto de investigação o projeto de emancipação veiculado pelo periódico Movimento da União Nacional dos Estudantes, publicado entre os anos de 1962 e 1963. O objetivo é identificar como as condições materiais da sociedade brasileira influenciaram no conceito de emancipação, presente nesse impresso estudantil, e as distinções entre este pensamento e as concepções elaboradas por Karl Marx e por Friedrich Engels. Fundamentado nas categorias totalidade e contradição, do materialismo histórico dialético, e tendo como fonte primária a revista Movimento, conclui que o projeto de emancipação difundido por este impresso estava inserido no contexto do movimento nacional e progressista brasileiro, registrado nos anos finais da década de 1950 e início dos anos 1960, e vinculado à ideologia burguesa liberal.

Palavras-chave: Imprensa Estudantil. União Nacional dos Estudantes. Emancipação.
\end{abstract}

\section{“MOVIMENTO UNE" NEWSPAPER (1962-1963): CHANNEL OF PROGRESSIVE THINKING}

ABSTRACT: This article is situated in the field of the history of Brazilian education and its object of investigation is the emancipation project propagated by the journal Movimento da União Nacional dos Estudantes (Movement of the National Union of Students) published between 1962 and 1963 . The objective is to identify how the material conditions of the Brazilian society influenced the concept of emancipation, present in this student printed matter, and the distinctions between this thought and the conceptions elaborated by Karl Marx and Friedrich Engels. Based on the categories totality and contradiction of dialectical historical materialism and having as its primary source the magazine Movimento, it concludes that the emancipation project spread by this form was inserted in the context of the Brazilian national and progressive movement, registered in the late 1950s and early 1960s, and tied to liberal bourgeois ideology.

Keywords: Student Press. National Union of Students. Emancipation.

\footnotetext{
1 Professora do Instituto Federal do Paraná - Irati. Doutoranda em Educação da Universidade Estadual de Ponta Grossa.

2 Profa. Dra. da Pós-Graduação em Educação da Universidade Estadual de Ponta Grossa. E-mail: misabelnasc@gmail.com
} 


\section{EL PERIÓDICO MOVIMIENTO DE LA UNE (1962-1963): UN CANAL DEL PENSAMIENTO PROGRESISTA}

RESUMEN: Este artículo se sitúa en el campo de la historia de la educación brasileña y tiene como objeto de investigación el proyecto de emancipación ventilado por el periódico Movimento da União Nacional dos Estudantes, publicado entre los años de 1962 y 1963. El objetivo es identificar como las condiciones materiales de la sociedad brasileña influenciaron en el concepto de emancipación, presente en ese impreso estudiantil y las distinciones entre este pensamiento y las concepciones elaboradas por Karl Marx y Friedrich Engels. Fundamentado en las categorías totalidad y contradicción del materialismo histórico dialéctico y teniendo como fuente primaria la revista Movimiento, concluye que el proyecto de emancipación difundido por ese impreso estaba inserto en el contexto del movimiento nacional y progresista brasileño, registrado en los años finales de la década de 1950 y principios de los años 1960, y vinculado a la ideología burguesa liberal.

Palabras clave: Prensa estudiantil. Unión Nacional de los Estudiantes. Emancipación.

\section{Introdução}

A imprensa escrita vem se configurando ao longo das últimas décadas como fonte primária e objeto de investigação de diferentes estudos na área da história da educação brasileira. Num primeiro momento, os pesquisadores desse campo se debruçaram na chamada imprensa de educação e de ensino ${ }^{3}$ e, posteriormente, revistas, jornais e folhetins de diferentes segmentos sociais e de conteúdo geral passaram a ser prestigiados pelos estudiosos, uma vez "[...] que os debates relativos à educação costumam encontrar nesta mídia um caminho para atingir amplos setores da população" (TOLEDO; SKALINSKI Jr., 2012, p. 265).

Entre os periódicos que estão ganhando visibilidade nas produções acadêmicas na área da história da educação, citam-se os impressos estudantis, como os de grêmios escolares, de associações literárias discentes e de agremiações políticas dos educandos. Sabe-se que a imprensa, como afirma

\footnotetext{
${ }^{3}$ Entende-se por imprensa de educação e de ensino aquela destinada ao público docente, a fim de disseminar projetos e princípios educativos.
} 
Renée Zicman (1985, apud OLIVEIRA, p. 90, 2011), pode ser em alguns casos o único registro do passado e por meio dela é possível conhecer a sociedade e seus variados elementos culturais, políticos e econômicos, permitindo ao historiador observar como os periódicos interferem e expressam determinadas realidades.

Na tentativa de colaborar com a história da educação pela imprensa estudantil, o presente artigo $^{4}$ possui como fonte primária o periódico Movimento, produzido pela União Nacional dos Estudantes (UNE) entre os anos de 1962 e 1963. A equipe editorial ${ }^{5}$ dessa revista, já em sua primeira edição, destacou que a mesma possuía como proposta ser o “[...] órgão oficial de todos os setores progressistas" (EDITORIAL, 1962, p. 3). Desse modo, esse impresso torna-se, nas mãos do historiador, uma abastada fonte de pesquisa sobre a concepção de sociedade, de cultura, de política e de economia dos dirigentes da UNE, bem como, de suas práticas militantes.

Em relação aos pressupostos teóricos, o estudo se fundamenta no materialismo histórico dialético. Segundo Marx e Engels (2007), são os indivíduos os produtores das ideias e estes as produzem a partir de suas condições materiais, ou seja, de seu processo de vida real. Essa assertiva, não exclui a noção de que a imprensa interfere na realidade, mas pressupõe a imprensa como a expressão ideológica dos sujeitos, portanto, estes devem ser contextualizados historicamente, uma vez que a intenção é compreender a base concreta que faz emergir essa ideologia.

A UNE, no início da década de 1960, alinhou-se às lutas da chamada Frente Progressista Brasileira (FPB), também denominada de Frente Única, constituída de partidos e associações políticas e intelectuais defensores da democracia, do nacionalismo e do desenvolvimento. No interior dessa campanha de reformas, definidas como revolucionárias, os dirigentes dessa entidade representativa, universitária, difundiu por meio do periódico Movimento vários pensamentos e valores, entre eles a ideia de emancipação.

Portanto, a partir do referencial teórico materialista, surgiram, as seguintes problemáticas de pesquisa: De que maneira as condições materiais da sociedade brasileira influenciaram a concepção

\footnotetext{
${ }^{4} \mathrm{O}$ presente artigo é resultado de uma reflexão preliminar de uma pesquisa doutoral em desenvolvimento no Programa de Pós-Graduação em Educação da Universidade Estadual de Ponta Grossa.

${ }^{5}$ Os textos e informes da revista Movimento sem autoria são nominados neste artigo como "Editorial".
} 
de emancipação presente na revista? Quais as contradições desse conceito, levando em consideração a noção de emancipação definida pelos filósofos Marx e Engels? Assim, o objetivo deste artigo é analisar o projeto de emancipação veiculado pelo periódico Movimento e identificar suas matrizes históricas a fim de corroborar com a história da educação pela imprensa estudantil sob o viés do materialismo histórico dialético.

\section{O pensamento progressista brasileiro e a UNE}

No mês de março de 1962, a UNE relançava o primeiro número da revista Movimento ${ }^{6}$. Segundo seus editores, a produção seria, a partir de então, mais planejada e sistematizada, pois as publicações anteriores eram esporádicas e relacionadas às demandas específicas da própria instituição estudantil, como congressos anuais ou acontecimentos políticos considerados importantes por essa agremiação.

A proposta dessa mídia, coordenada por César Guimarães, por Arnaldo Jabor e por Marcello Cerqueira ${ }^{7}$, era dialogar com o público estudantil e geral sobre as problemáticas do Brasil. Segundo a equipe Editorial (1962), o impresso tinha como intenção interpretar a realidade do ponto de vista cultural alinhado a uma interpretação considerada correta pela UNE acerca da conjuntura nacional e, por meio de uma filtragem, impediria o unilateralismo ideológico.

A imprensa foi utilizada pela UNE para dialogar com os estudantes brasileiros divulgando um conjunto de ideias consideradas como verdadeiras para a superação das contradições sociais existentes naquele contexto histórico. Portanto, o periódico Movimento é compreendido, neste estudo, como manifestação do pensamento dessa entidade e não de todos os universitários

\footnotetext{
${ }^{6}$ O periódico Movimento é uma publicação da União Nacional dos Estudantes que circulou no Brasil entre os anos de 1962 e 1963. Por meio da sua Editora Universitária, a UNE produziu onze números nesse período, sendo sete edições em 1962 (março, maio, junho, julho, setembro, outubro e novembro) e quatro edições em 1963 (fevereiro, março, abril, maio). A revista possuía um custo de $\mathrm{Cr} \$ 50$ cruzeiros e sua tiragem inicial foi de seis mil exemplares e a última de 10 mil. Em geral, as matérias abordavam questões relacionadas à dimensão econômica, política, educacional e cultural do nosso país. Nesse artigo, os escritos dessa fonte são apresentados na grafia original.

${ }^{7}$ Guimarães, Jabor e Cerqueira eram estudantes de direito no início da década de 1960 e possuíam experiência na imprensa estudantil, por trabalharem no Jornal O Metropolitano, órgão da União Metropolitana dos Estudantes (UME) com sede no Rio de Janeiro.
} 
brasileiros. Para Marx e Engels (2007), o ato de representar e o pensamento dos indivíduos têm origem na sua organização material, logo, é preciso analisar como os sujeitos estudantis se comportavam materialmente na sociedade.

Como país capitalista, o Brasil, no início de 1960, era marcado por vários elementos oriundos desse modo de produção. Como, por exemplo, as lutas de classes devido ao domínio dos meios de produção pela burguesia; desigualdades sociais e culturais; dicotomia entre cidade e campo, bem como, trabalho intelectual e manual; exploração do trabalho; acúmulo de capital nas mãos da minoria e um Estado representativo desses interesses.

Além dessa realidade, o Brasil, devido ao seu passado colonial de exploração e por ter vivenciado uma industrialização tardia e dependente, apresentava outras contradições. Entre elas, destacam-se a dominação imperialista no campo econômico e cultural; estrutura agrária latifundiária; e democracia representativa fragilizada em virtude do alto número de analfabetos ${ }^{8}$ sem direito ao voto.

De 1930 até 1964, a sociedade brasileira passou por muitas transformações econômicas, sociais, políticas e culturais. A industrialização ${ }^{9}$ se dinamizou no país, com apoio estatal durante o governo de Getúlio Vargas (1930-45) e com amplo estímulo ao capital estrangeiro no período presidencial de Juscelino Kubitschek (1956-61). Vale ressaltar que um dos fatores dessas mudanças foi a segunda guerra mundial, ao ocasionar surto industrial, aceleração do processo inflacionário, exploração das riquezas nacionais, rápido empobrecimento e politização das massas e maior articulação da burguesia nacional reivindicando seus interesses particulares (SODRÉ, 1963).

Essa nova configuração econômica exigia uma maior capacitação profissional. Dessa maneira, a educação formal técnica e tecnológica passou a ser reivindicada tanto por setores governistas, para atender aos anseios do capitalismo industrial, como da classe trabalhadora, que via na escolarização a possibilidade de ascensão social. Percebe-se que, nesse contexto histórico, a

\footnotetext{
${ }^{8}$ Segundo o coordenador do Movimento de Alfabetização da UNE, em 1960 o Brasil possuía 65 milhões de habitantes e destes cerca de 15 milhões não participavam diretamente do processo político brasileiro devido à legislação eleitoral brasileira da época (ABEND, 1962, p. 05).

9 É preciso destacar que o capital estrangeiro financiou o processo da industrialização brasileira em suas diferentes etapas (PRADO Jr., 1981).
} 
industrialização e a educação se tornam baluartes de projetos desenvolvimentistas para o Brasil.

Concomitante, ocorre nessas décadas o crescimento da classe proletária, uma classe que se forma da evolução do capitalismo industrial e que se constitui não pela "[...] pobreza naturalmente existente, mas a pobreza produzida artificialmente" (MARX, 2010, p. 156). Logo, com a proletarização da sociedade, aumenta o descontentamento e a mobilização dos trabalhadores, representando um perigo à ordem vigente, sustentada pela burguesia e pelo Estado (ENGELS, 1847).

Com a expansão industrial e a tecnologia alcançando as zonas rurais, o êxodo de pessoas destas regiões em direção aos espaços urbanos aumentou consideravelmente, até que, na década de 1960, o Brasil passou a ter uma população majoritariamente urbana. Com um número maior de pessoas concentradas nas cidades, cresceu a concorrência pelo emprego, a organização desses sujeitos em associações políticas e a procura pela educação em seus mais variados níveis. Em relação ao ensino superior, observa-se segundo dados de Helena Sampaio (1991), que o número de matrículas nesse nível de ensino aumentou quase 90\% entre 1950 e 1960, mas isto ocorreu principalmente por causa da oferta de educação privada que atingiu em média $44 \%$.

Nesse contexto urbano-industrial, grupos de intelectuais, partidos políticos e movimentos sociais passaram a defender teses para acelerar o processo revolucionário que retiraria o país do subdesenvolvimento, levando-o à emancipação. Essas ideias foram denominadas, na época, de progressistas e seus grupos de forças progressistas. De maneira sucinta, as teses afirmavam que o imperialismo e o sistema latifundiário eram os principais entraves ao crescimento econômico nacional, portanto, era preciso combatê-los primordialmente. Além disso, a ampliação democrática era também imprescindível para o desenvolvimento do país.

Antes de analisar o significado de emancipação presente nas páginas do periódico Movimento da UNE e comungados por esses diferentes grupos progressistas, se faz necessário apresentar o que Marx e Engels, filósofos do socialismo científico, entendiam acerca de emancipação, no sentido de identificar as contradições do pensamento progressista. Para Marx, militante político do comunismo, emancipar-se não se tratava somente de possuir autonomia política, mas, sobretudo, voltar-se à natureza humana, eliminando toda e qualquer forma de dominação econômica e suas frações políticas e culturais. 


\begin{abstract}
A emancipação humana só será plena quando o homem real e individual tiver em si o cidadão abstracto; quando como homem individual, na sua vida empírica, no trabalho e nas suas relações individuais, se tiver tornado um ser genérico; e quando tiver reconhecido e organizado as suas próprias forças (forces propres) como forças sociais, de maneira a nunca mais separar de si esta força social como força política (MARX, 1843, p. 30).
\end{abstract}

Nessa perspectiva, a emancipação do homem nada mais é do que um processo de libertação econômica e consequentemente histórica. Segundo Marx, ao se apropriar da totalidade existente das forças produtivas o proletariado, além de atingir o seu eu, poderia garantir sua existência e desenvolver integralmente suas aptidões e seus sentidos. Dessa maneira, o antagonismo de classe, existente na sociedade capitalista não existiria na sociedade comunista, pois nesta o trabalho tornarse-ia a primeira necessidade vital e o princípio de cada um segundo suas capacidades, a cada um segundo suas necessidades se transformaria em realidade (MARX; ENGELS, 2012).

Conforme os pressupostos teóricos do socialismo científico, a emancipação humana se tornaria real após a derrubada do sistema capitalista de produção. Essa emancipação, ao contrário da emancipação política, é “[...] plena, livre de contradições [...]” (MARX, 1843, p. 10). Por isso, nesse viés de pensamento e de militância, a emancipação humana e universal surge a partir da ruptura radical com a ordem capitalista vigente e de todos os elementos que a compõe.

No Brasil, durante a década de 1950 e 1960, grupos como o Instituto Superior de Estudos Brasileiros (ISEB), o Partido Comunista Brasileiro (PCB) e a Ação Popular (AP), comungaram do pensamento progressista, cujo, propósito era a emancipação nacional. As concepções dessas forças progressistas serão analisadas sucintamente, em razão da influência teórica que cada uma delas teve no posicionamento político da UNE.

O ISEB nasceu em 1955, sob a tutela estatal, e estava vinculado ao Ministério da Educação e Cultura. Sua proposta era construir teoricamente um projeto de desenvolvimento nacional alinhado ao programa de aceleração econômica do governo de Juscelino Kubitschek. Os teóricos ${ }^{10}$ desse instituto divergiam em relação às concepções de nacionalismo e desenvolvimento, mas o que os

\footnotetext{
10 Entre os teóricos do ISEB destacam-se Hélio Jaguaribe, Roland Corbisier, Alberto Guerreiro Ramos, Nelson Werneck Sodré, Cândido Mendes, Álvaro Vieira Pinto, Miguel Reale e Sérgio Buarque de Holanda.
} 
aproximava era a ideia de uma contradição entre as classes que defendiam os interesses nacionais e outras vinculadas aos interesses imperialistas.

Segundo Toledo (1997, p. 136), a falta de um estudo isebiano mais criterioso sobre o tema das classes sociais, caracteriza um “[...] dos impasses da ideologia nacionalista [...]". O autor apontou que uma das razões disso seria a pobreza bibliográfica sociológica acerca dessa temática por parte dos intelectuais do ISEB. Mas é possível inferir, também, que tal limitação advém do fato de esse projeto ser fruto de um aparato governamental, pois no modo de produção capitalista a burguesia, ao assumir o poder político, procura fazer do Estado seu representante oficial.

Portanto, ao partir dessa premissa não teria como um Estado que representava a burguesia liberal financiar um projeto de teorização nacional-desenvolvimentista, cujo âmago da estrutura capitalista fosse evidenciado e debatido. Por isso, acredita-se que a questão das classes sociais não foi investigada racionalmente e empiricamente de maneira profunda. Vale ressaltar que os estudiosos isebianos, embora possuíssem suas subjetividades enquanto pensadores, estavam também materialmente ligados a um modo de produção que impede de variadas maneiras ${ }^{11}$ a consciência de classe e a construção de um projeto de revolução radical que objetiva uma emancipação humana universal, tal como foi proposta pelos filósofos Marx e Engels.

Para Engels (1880), a limitação dos pensadores se dá pelas fronteiras de seu momento histórico, logo o ISEB, ao centrar-se na noção de que o nacionalismo, expressava a libertação e o imperialismo o maior obstáculo ao desenvolvimento do Brasil, acaba por processar uma visão reformista de caráter burguês. Suas ideias se disseminaram nas academias, nos movimentos sociais, nos planos governamentais e nos partidos políticos que constituíram a FPB entre os anos de 1955 e 1964, por isto sua importância como centro de referência teórica nessa época. Na revista Movimento, percebe-se a influência dos isebianos, seja por meio de suas contribuições textuais como as de Carlos Estevam Martins, Paulo de Castro, Ignácio Rangel e Wanderley Guilherme, seja como as propagandas de livros publicados por estes teóricos e até mesmo nas posições da UNE frente à luta anti-imperialista.

11 No modo de produção capitalista a burguesia, donos dos meios de produção, utiliza de vários mecanismos para representar seus interesses como universais, mantendo-se assim no poder. Entre esses instrumentos cita-se, por exemplo, o Estado, a escola formal e a mídia. 
Em relação aos partidos políticos que constituíram a FPB, destacou-se o PCB. Sua influência é materialmente visível nos grupos de esquerda do país no período, especialmente nas décadas de 1950 e 1960. Dirigentes da UNE e os responsáveis pelo periódico Movimento, ou eram simpatizantes ou filiados desse partido; e, na revista, há algumas contribuições escritas dos comunistas: Carlos Nelson Coutinho, Oduvaldo Vianna Filho, Ferreira Gullar, Carlos Diegues e Mario Alves.

A importância de analisar as teses revolucionárias do PCB nessa época ocorre pelo fato de ter sido uma referência na construção de teorias e práticas de parte da intelectualidade e dos movimentos sociais, como o estudantil. As ideias desse partido, colaboraram diretamente na tentativa de ampliar a frente única nacionalista e democrática brasileira que reunia representantes políticos da Frente Parlamentar Nacionalista (FPN) e diferentes classes sociais progressistas, representadas pelas mais variadas associações.

Após o dossiê Kruschev ${ }^{12}$, o PCB passou a reavaliar suas concepções e ações, tendo como ponto de partida as peculiaridades da sociedade brasileira. $O$ resultado de tal exame foi um documento elaborado pelo comitê central do partido, intitulado Resolução de 1958 do $P C B$, e neste é possível perceber as diretrizes no que tange ao processo de desenvolvimento econômico do país. Segundo o partido, de tendência marxista-leninista, a realidade nacional assim se caracterizava:

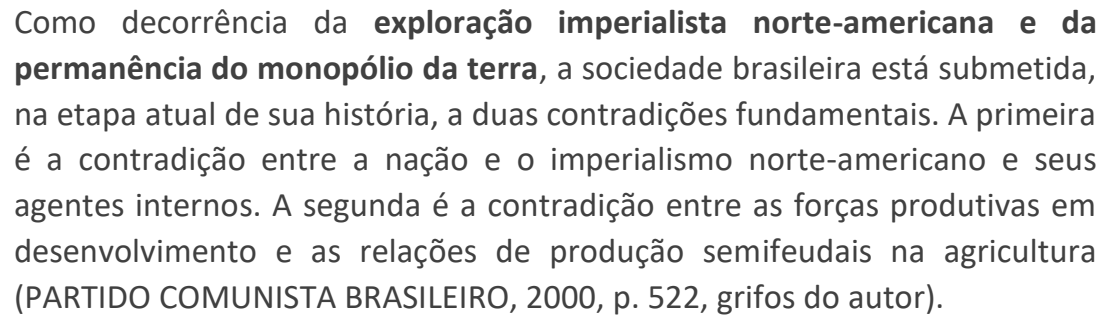
permanência do monopólio da terra, a sociedade brasileira está submetida, na etapa atual de sua história, a duas contradições fundamentais. A primeira é a contradição entre a nação e o imperialismo norte-americano e seus agentes internos. A segunda é a contradição entre as forças produtivas em desenvolvimento e as relações de produção semifeudais na agricultura (PARTIDO COMUNISTA BRASILEIRO, 2000, p. 522, grifos do autor).

As contradições em destaque se sobressaíam em relação à contradição das lutas de classes o

12 O dossiê Kruschev, divulgado pelo secretário-geral do Partido Comunista da União Soviética em 1956, durante o XX Congresso do Partido Comunista revelou ao mundo as ações repressivas e autoritárias do governo de Stálin, provocando uma reorganização dos comunistas em diferentes países. 
modo de produção capitalista vigente no Brasil. Sendo assim, a maior luta defendida pelo PCB, naquele momento histórico, era a empreitada anti-imperialista norte-americana, como se evidencia em várias partes da resolução.

Na configuração econômica e social brasileira, os comunistas ${ }^{13}$ identificaram o antagonismo entre as forças nacionais e progressistas versus as forças entreguistas. As primeiras constituídas pelo proletariado, camponeses, pequena burguesia urbana, burguesia e latifundiários dissociados do imperialismo norte-americano e as últimas formadas por setores de latifundiários e da burguesia, como sócios empresariais e agentes bancários e comerciais, alinhados ao imperialismo (PARTIDO COMUNISTA BRASILEIRO, 2000). Nota-se que havia classes bem heterogêneas agrupadas do mesmo lado e isto decorria da necessidade imprescindível de unir grupos, que, embora possuíssem interesses divergentes, deveriam agregar forças a fim de aniquilar o maior entrave ao desenvolvimento do capitalismo nacional.

O PCB defendia que a etapa revolucionária naquele contexto brasileiro era a expansão do capitalismo independente e isto representava a emancipação nacional. Logo, a revolução brasileira se caracterizava primeiramente como anti-imperialista, antifeudal ${ }^{14}$, nacional e democrática, a ser realizada por meios pacíficos da legalidade democrática e constitucional. Esses elementos constituíam o caráter progressista do partido e dos diferentes sujeitos individuais e coletivos que comungavam dessa premissa, pois "[...] é na luta contra o imperialismo norte-americano e os seus agentes internos que as forças progressistas da sociedade brasileira podem acelerar o desenvolvimento econômico independente e o processo de democratização da vida política do país" (PARTIDO COMUNISTA BRASILEIRO, 2000, p. 519).

A prioridade dessa luta permitiu a difusão da tese de uma aliança proletário-burguesa, uma vez que o proletariado sofreria muito mais com a espoliação imperialista do que com a evolução do sistema capitalista. Conforme os militantes do PCB, essa aliança deveria ser dirigida pelo proletariado, por ser considerada a única classe capaz de manter a solidez política da Frente Única. Porém, a classe

13A expressão comunista, neste trabalho, refere-se aos membros do Partido Comunista Brasileiro e não do Partido Comunista do Brasil (PC do B).

14 Para o PCB o capitalismo ao ser introduzido na agricultura brasileira conviveu com a grande concentração de terras e com antigas relações denominadas pelos comunistas como semifeudais. 
proletária, naquele período, ainda não possuía as condições materiais necessárias para liderar tal aliança. Entre essas condições destaca-se, por exemplo, o alto índice de analfabetos sem direito ao voto e a baixa representatividade sindical.

O posicionamento do PCB gerou muitas polêmicas por parte de outros grupos de esquerda que questionavam a aliança entre operários e burgueses. Até mesmo militantes do partido, como Mário Alves (1963), teceu algumas reflexões na revista Movimento sobre isto, apontando que as posições da burguesia nacional não possuíam caráter revolucionário e o fato de temer o avanço socialista fazia dela uma classe conciliadora aos interesses imperialistas.

Essa proposta de aliança, de certa maneira, desvinculava o imperialismo do capitalismo nacional, que na verdade são decorrentes da mesma base, ou seja, do modo de produção capitalista. Para o socialismo científico, emancipação significava a abolição da propriedade privada dos meios de produção e consequentemente o fim da luta de classes. Por isso, tanto a exploração econômica de um país sobre o outro, como a exploração de uma classe sobre a outra são desdobramentos da propriedade privada burguesa. Logo, o grupo que nega tal prerrogativa não tem como finalidade de sua militância a concretização da igualdade social, anunciada por Marx e Engels como fruto da derrubada do sistema capitalista.

Sobre os limites da burguesia no processo revolucionário anti-imperialista, destaca-se a análise crítica do isebiano Wanderley Guilherme dos Santos, publicado no periódico Movimento. Para o filósofo, a burguesia estava assumindo papel hegemônico entre as forças progressistas e isto traria algumas contradições, como, por exemplo, o fato de não poder reconhecer o imperialismo como fenômeno objetivo, pois se isto ocorresse teria que questionar a sua própria essência que é o modo de produção capitalista (SANTOS, 1962). Assim, a burguesia não iria promover sua autocondenação e isto lhe retirava o potencial de liderança nesse projeto de emancipação.

Segundo o PCB, o movimento nacionalista e democrático dos anos finais da década de 1950 exigia das forças progressistas uma pauta em comum. Entre os seus itens estavam uma política exterior independente e de paz, o desenvolvimento autônomo da economia nacional, medidas de reforma agrária favoráveis aos camponeses, a elevação do nível de vida da população e ampliação da legalidade democrática (PARTIDO COMUNISTA BRASILEIRO, 2000).

Todos os pontos citados foram contemplados nas onze edições da revista Movimento, 
publicadas entre 1962 e 1963, porém, a questão da reforma agrária é a menos expressiva de todas ${ }^{15}$. Portanto, se as teses comunistas estavam presentes no impresso estudantil é porque a UNE acreditava que elas seriam a expressão autêntica das problemáticas brasileiras. $\mathrm{O}$ fato de a burguesia nacional liderar o processo revolucionário, apesar de o PCB defender o papel decisivo do proletariado, representa a limitação do projeto emancipatório, comprometendo, assim, a Frente Única e dificultando até mesmo a consolidação da luta anti-imperialista.

Nota-se, que tanto a ideologia desenvolvida pelo ISEB, como o projeto de revolução do PCB comungavam da concepção de que o atraso econômico brasileiro era proveniente do imperialismo e da estrutura agrícola de traços "feudais". Logo, ao empregar forças para aniquilar esses dois obstáculos se alcançaria o desenvolvimento do capitalismo nacional, ou seja, a emancipação, provocando assim outras transformações sociais.

Além dessas duas instituições, não se pode negar a influência direta da AP na UNE e consequentemente na revista Movimento. A partir de 1961 até 1964, os três presidentes da entidade universitária pertenciam à AP, sendo respectivamente: Aldo Arantes (1961-62), Vinícius Caldeira Brandt (1962-63) e José Serra (1963-64). Essa entidade tem sua origem na "[...] dissenção entre o grupo estudantil da Juventude Universitária Católica (JUC) e a hierarquia religiosa" (POERNER, 1979, p. 188). Entre seus principais nomes estavam o sociólogo Herbert José de Sousa e o padre Henrique Vaz, ambos com artigos publicados no Movimento.

Uma das principais fontes históricas da AP é seu Documento Base, datado de 1963, em que é possível identificar os fundamentos teóricos de sua visão, opção e ação, enquanto organização política. Embora comungasse da necessidade da luta anti-imperialista e defendesse a união de diferentes grupos para tal realização, a entidade defendia a mobilização popular "[...] contra a dupla dominação capitalista (internacional e nacional) e feudal" (AÇÃO POPULAR, 1963, p. 14).

A perspectiva do socialismo relacionado com o humanismo permitiu aos militantes da Ação Popular ir além das concepções isebianas e do PCB e estabelecer críticas às experiências socialistas

15 Segundo o comitê central do PCB, os camponeses constituíam a massa mais numerosa da nação, porém a sua organização política era pouco expressiva (PARTIDO COMUNISTA BRASILEIRO, 2000), e talvez isto tenha contribuído para que o tema da reforma agrária fosse pouco abordado na revista Movimento. 
ocorridas em diferentes nações desde 1917. Para a entidade "O que interessa é garantir a liberdade de desenvolvimento das pessoas, a possibilidade da sua expressão e da expressão de sua vontade" (AÇÃO POPULAR, 1963, p. 11).

Observa-se, a partir desse pressuposto teórico, que a AP se colocou na luta pelo homem e com o homem, combatendo toda e qualquer força que o destruísse, ou seja, tanto o imperialismo, como o capitalismo nacional e a organização agrária definida como feudal. O presidente da UNE e militante da AP salientou no início de seu mandato que sua postura cristã não era a de um cristianismo sem consequência e sem obras e, sim, de um cristão que lutava ao lado de tantos outros para que o povo brasileiro tivesse dias melhores e mais humanos (BRANDT, 1962).

Para Brandt (1962), a frente de esquerda representava a luta pela libertação popular e a superação daquele momento histórico por outro em que o homem estaria conciliado consigo mesmo. É notável no posicionamento do estudante a relação entre cristianismo e marxismo, o que revela a permanência dos princípios cristãos na AP, após o rompimento com as entidades estudantis católicas ${ }^{16}$, e a defesa do socialismo como etapa revolucionária. Nesse sentido, o que o país estava vivenciando no início da década de 1960, segundo a AP, era uma etapa pré-revolucionária.

A população brasileira, em 1962, era de 77 milhões, sendo os universitários 0,13\% desse total demográfico. Logo, a UNE representava cerca de 100 mil universitários, dado que expressa, por exemplo, a ausência de grandes investimentos em ensino superior, ciência e tecnologia nacional. No Brasil, prevaleciam os interesses da burguesia, devido ao seu modo de produção capitalista, portanto, a burguesia brasileira alinhada ou não ao imperialismo não possuía como proposta universalizar a educação, em especial a superior, uma vez que esta poderia se transformar num importante instrumento de conscientização das massas.

No contexto democrático dos anos iniciais de 1960, a UNE fez parte da Frente Única de mobilização pelas reformas de base, junto a outros grupos já citados. Como entidade políticorepresentativa de nível nacional, seu papel era mobilizar o público estudantil, muitas vezes isolado pelas questões geográficas e pela carência de compreensão das problemáticas brasileiras, em prol do

16 A Ação Popular surgiu do rompimento com a Juventude Universitária Católica (JUC) e da Juventude Estudantil Católica (JEC). 
desenvolvimento nacional.

Com a proposta de conscientizar os universitários sobre assuntos educacionais, econômicos, políticos e culturais e ao mesmo tempo de se afirmar como força progressista, a UNE realizou seminários regionais e assembleias estudantis. Além do mais, colaborou na formação de centros populares de cultura, apoiou projetos editoriais como a publicação Cadernos do Povo Brasileiro e livros da Editora Universitária e reorganizou o periódico Movimento.

A imprensa se tornou para a UNE um canal de comunicação e propaganda. Um espaço de difusão do pensamento progressista, em que vários intelectuais, estudantes, artistas, representantes políticos e empresariais colaboravam para que a tese da emancipação nacional ganhasse expressividade entre os leitores da revista Movimento. Para os financiadores desse periódico, era vital essa forma de ação, uma vez que isto potencializaria a luta anti-imperialista e anti-latifundiária, denominada de revolucionária.

\section{Emancipação no periódico Movimento}

A UNE, desde sua fundação, em 1937, vem acompanhando o movimento histórico brasileiro, até porque ela é fruto deste movimento. Nasceu a partir de uma série de transformações, em que se destacam o crescimento urbano-industrial, a Revolução de 1930, a institucionalização da educação por meio de criação de decretos e ministérios e as contradições do governo de Getúlio Vargas. Sobreviveu ao Estado Novo, lutou pelo engajamento do Brasil ao lado dos países Aliados na segunda guerra mundial e conquistou uma sede nesse mesmo governo, obtendo, assim, certo reconhecimento governamental e da sociedade civil.

Com a democratização do país entre 1945-64, a UNE expandiu suas plataformas de luta e parcerias com forças progressistas. Entre suas principais campanhas, destaca-se "O petróleo é nosso", mobilização em defesa do monopólio estatal do petróleo brasileiro. A participação da entidade ao lado dos movimentos pela alfabetização, democracia e desenvolvimento nacional permitiu seu reconhecimento como vanguarda nas campanhas pelas reformas de base, no início dos anos de 1960, sendo até mesmo intitulada como o Quarto Poder no período final do governo João Goulart, pela socióloga Marialice Foracchi (1965).

Como foi observado, o número de universitários no Brasil era muito baixo comparado à população total, mas o que incomodava os setores políticos conservadores era a representatividade 
da $U N E^{17}$, somando-se às forças progressistas. Os jovens que ingressavam na universidade e que posteriormente se tornavam lideranças das entidades estaduais e nacional provinham majoritariamente da classe média e da burguesia e encontravam nas associações e partidos de esquerda uma forma de lutar por reformas educacionais, concebidas como uma etapa da transformação da realidade brasileira.

O fato de ser estudante não retira do sujeito universitário o pertencimento de sua classe ou a negação de uma classe na qual não deseja se manter. Todavia, enquanto membros da classe média e burguesa, defensores do capitalismo de cunho nacionalista e temerosos da crescente proletarização, observaram na ideologia progressista uma via revolucionária que canalizava seus interesses mais imediatos.

A pauta principal da entidade universitária, no início da década de 1960, foi a reforma universitária, pois acreditava que a universidade estava desintegrada da realidade social brasileira e de suas exigências imediatas naquele contexto, ou seja, a emancipação econômica. Segundo a UNE (UNIÃO NACIONAL DOS ESTUDANTES, 1962a), a instituição universitária era parasitária e alienada, pois não garantia a participação efetiva discente em seus órgãos administrativos, não atendia prioritariamente a maioria da população devido à carência de bolsas de estudos e ao tempo integral, não estimulava a investigação científica e não estava cumprindo sua função social de servir ao povo nas suas mais variadas aspirações. Mas para que tal realidade se transformasse, o país precisaria de outras reformas sociais ${ }^{18} \mathrm{e}$, por isto, o apoio estudantil na sua consolidação:

[...] reforma agrária, reforma constitucional, reforma bancária, são algumas das reformas que estão sendo exigidas urgentemente e para isso precisamos também estar alertas, incentivando e cooperando em tudo que estiver ao nosso alcance para que estas metas sejam atingidas. Desta maneira, estaremos construindo um Brasil novo, com bases sólidas para um desenvolvimento harmônico em todos os ramos de atividade (UNIÃO NACIONAL DOS ESTUDANTES,1962a, p. 4).

$17 \mathrm{O}$ fato que revela o incômodo provocado pela UNE aos setores políticos conservadores foi o incêndio promovido pelo novo governo, logo após o golpe civil-militar em 1964 na sede da entidade, localizada na Praia do Flamengo.

18 Essas reformas elencadas pela UNE faziam parte das chamadas reformas de base e conquistaram notoriedade governamental no Comício da Central do Brasil em 13/03/1964, gerando reação de grupos políticos e de parte da sociedade que apoiaria o golpe civil-militar ocorrido neste mesmo mês. 
Para alcançar esse novo Brasil, almejado pela UNE e por outras entidades que formavam as forças progressistas naquele período histórico, estava primeiramente a luta contra os entraves ao desenvolvimento econômico do capitalismo nacional. Era preciso, portanto, conscientizar a população desses obstáculos e dessa maneira a revista Movimento, desde sua primeira reedição, denunciou o imperialismo norte-americano e o sistema latifundiário como promotores do atraso e das disparidades sociais do país.

No artigo "Panamericanismo: essência e futuro", Paulo de Castro conceituou panamericanismo como a hegemonia política e o domínio econômico dos Estados Unidos da América (EUA) sob as nações da América Latina. Segundo o autor, a burguesia norte-americana, com a cumplicidade das oligarquias nacionais procurava manter a sociedade brasileira na "minoria econômica e mental". Se posicionar contra isso representava a luta pela independência econômica, e nesta empreitada o Brasil deveria aproveitar o fato de a burguesia nacional, classe média e trabalhadores estarem insatisfeitos com o imperialismo. Esse professor do ISEB, que nesse mesmo ano publicou a obra Subdesenvolvimento e Revolução ${ }^{19}$, procurou denunciar a espoliação estadunidense na região latino-americana e, ao mesmo tempo, estimular o movimento nacionalista brasileiro a manter-se firme no combate "[...] pela nossa emancipação" (CASTRO, 1962, p. 6).

No seio da ideologia progressista estava a veneração da revolução cubana pela UNE, não devido à implantação do socialismo e sim pelo fim da exploração econômica e política estadunidense na ilha. Apesar de as forças progressistas serem formadas por entidades com divergências políticas, as mesmas se uniram prioritariamente em torno da luta anti-imperialista para consolidação do capitalismo nacional e isto era o que entendiam e defendiam como emancipação.

Sobre Cuba, Marini Filho fez uma exposição sobre este país antes e após a revolução ocorrida em 1959, destacando as principais conquistas econômicas, sociais e culturais até 1962. Com o título Cuba: território livre da América, a matéria direcionava o leitor a perceber os ganhos de uma nação quando livre do imperialismo estadunidense. Cita Marini Filho (1962, p. 07-08), por exemplo, que as “[...] empresas de eletricidade e comunicação pertenciam a monopólios americanos da mesma forma

19 Na edição número 3, de junho de 1962, a revista Movimento publicou uma síntese do livro Subdesenvolvimento e Revolução de Paulo de Castro. 
que as principais companhias de transportes, os bancos, o controle de ações nas Sociedades Anônimas e as melhores terras cultiváveis" e que após 1959 aquilo tudo foi devolvido ao povo cubano.

Uma descrição mais detalhada sobre a revolução cubana, do ponto de vista teórico e prático, encontra-se no Roteiro explicativo do socialismo tropical de Paulo Derengosqui, que esteve na ilha e, segundo suas palavras, voltava entusiasmado pelo que tinha observado. Nesse balanço, comparou Cuba com outras nações da América Latina, descreveu as reformas urbana, agrícola e educacional, salientou discursos de Fidel às crianças cubanas e falas de Che Guevara sobre a guerra da morte em que "[...] o campo do imperialismo diminui com a libertação de cada país" (Derengosqui, 1962, p. 23).

Luiz Alberto Gomes de Souza, um dos fundadores da AP, em matéria publicada na revista Movimento em 1963, definiu Sierra Maestra como o ponto de partida da emancipação latinoamericana e Fidel Castro como o precursor desta vitória. Ao tecer considerações sobre a temática do neutralismo como outra possibilidade de posicionamento frente à dicotomia entre liberalismo e marxismo, o autor chegou a enfatizar que o próprio neutralismo, ou seja, o não alinhamento com a política econômica dos EUA e da União das Repúblicas Socialistas Soviéticas (URSS) era um meio de emancipação (SOUZA, 1963). A partir desse pensamento, observa, mais uma vez, que a experiência cubana é colocada como exemplo aos povos latino-americanos na luta anti-imperialista estadunidense e não na implantação do sistema socialista.

Durante o Congresso Continental de Solidariedade a Cuba, ocorrido no Rio de Janeiro, entre os dias 26 e 30 de março de 1963, vários representantes políticos se pronunciaram pelo apoio a Cuba na luta contra o bloqueio econômico imposto pelos EUA. Conforme exposto na matéria intitulada Cuba não está só, o congresso teria sido convocado pelas forças populares e progressistas da América Latina e entre os brasileiros estavam Sérgio Magalhães, presidente da FPN; Osvaldo Pacheco do Comando Geral dos Trabalhadores (CGT); Bocayuva Cunha, líder do Partido Trabalhista Brasileiro (PTB); e Vinícius Caldeira Brandt, presidente da UNE.

Visualiza-se por meio dos depoimentos dos brasileiros, a ideia de que o imperialismo era o maior entrave à emancipação nacional. Magalhães, por exemplo, reitera o importante papel da revolução cubana como referência ao processo revolucionário latino-americano, uma batalha que segundo ele integrava todas as nações do mundo oprimidas pelo imperialismo (CUBA, 1963). Na mesma direção, expressou o líder do PTB ao denunciar que o imperialismo internacional por meio dos monopólios e trustes promovia o atraso e a exploração desumana (CUBA, 1963). E, finalmente, o 
gestor estudantil reforça a mesma visão:

\begin{abstract}
Defender Cuba é dever de todo estudante brasileiro consciente, porque defender Cuba é defender o Brasil. Porque Cuba ainda não está livre! livre dos bloqueios e das agressões armadas do imperialismo e o povo brasileiro também não se libertou da doença, da fome, do analfabetismo e principalmente do imperialismo causador da miséria do povo. Por isso, neste momento, Cuba e Brasil se dão as mãos em busca da liberdade (CUBA, 1963, p. 17).
\end{abstract}

O atraso econômico, a exploração humana, as desigualdades sociais e o analfabetismo foram concebidos por esses três representantes progressistas como resultado direto do imperialismo e não do sistema capitalista, que nem chega a ser mencionado em suas falas. $O$ único que fez certa menção acerca da luta de classe, embora, bastante genérica, foi o primeiro secretário do CGT ao proferir que não haveria divisão entre os proletários e sendo uma só família o proletariado brasileiro estaria ao lado dos trabalhadores do mundo todo (CUBA, 1963).

A postura de Osvaldo Pacheco provavelmente é fruto de sua identidade com a classe proletária, uma vez que trabalhou como estivador e era militante do PCB. Ao contrário, Sérgio Magalhães e Bocayuva Cunha possuíam formação superior em engenharia e Vinícius Caldeira Brandt, na época, cursava economia, revelando assim a origem elitista de tais representantes e o vínculo direto com o pensamento progressista.

A revista Movimento divulgou reflexões mais complexas acerca das problemáticas brasileiras vinculadas ao modo de produção capitalista, mas a ideologia predominante no impresso é a ênfase ao imperialismo e, em segundo plano, à estrutura agrícola latifundiária como maiores entraves à emancipação nacional. No contexto da revolução industrial, durante o século XIX, Marx e Engels produziram obras que analisaram criticamente o modo de produção capitalista e seus impactos negativos às classes trabalhadoras. Esses pensadores defenderam a abolição desse sistema por meio da revolução proletária e propuseram a possibilidade do comunismo. Para eles, "No lugar da velha sociedade burguesa, com suas classes e antagonismos de classes, surge uma associação na qual o livre desenvolvimento de cada um é a condição para o livre desenvolvimento de todos" (MARX; ENGELS, 2012, p. 69).

Para Marx e Engels, a emancipação humana não seria possível de se materializar na sociedade capitalista, pois nela os antagonismos de classes impedem o pleno desenvolvimento do indivíduo e consequentemente o de todas as pessoas. Nesse sentido, era preciso suprimir a estrutura 
que alimentava esse antagonismo, ou seja, o modo de produção capitalista, pois:

\begin{abstract}
No curso do desenvolvimento, uma vez desaparecidas as diferenças de classe e estando toda a produção nas mãos dos indivíduos associados, o poder público perde seu caráter político. O poder político, em seu sentido real, é o poder organizado de uma classe para a opressão de outra. Se, na luta contra a burguesia, o proletariado, por necessidade, se une numa classe, torna-se a classe dominante por meio de uma revolução e, como classe dominante, se vale de seu poder para abolir as velhas relações de produção, com isso ele abole também as condições para a existência do antagonismo de classes, abole as próprias classes e, desse modo, sua própria dominação como classe (MARX; ENGELS, 2012, p. 69).
\end{abstract}

A UNE, durante os anos iniciais de 1960, não colocou como bandeira principal de suas campanhas denominadas revolucionárias a eliminação do capitalismo para concretizar o desenvolvimento nacional. E, nesse sentido, é preciso destacar que as limitações eram materiais, pois, majoritariamente os estudantes do ensino superior no Brasil nessa época, representavam uma parcela minúscula comparada à população total e também em relação aos alfabetizados, devido as suas origens sociais mais abastadas se comparadas aos filhos de trabalhadores rurais e urbanos. Por isso, as propostas de transformações estruturais defendidas pela UNE careciam de uma análise crítica mais radical da sociedade burguesa, o que levou a entidade universitária a se fixar num projeto de nação, cujas relações de produção e de trabalho continuariam acarretando antagonismos de classes.

Na revista Movimento, as discussões progressistas estavam vinculadas à luta antiimperialista, anti-latifúndiária, democrática, nacionalista e desenvolvimentista. Esses são os cinco pilares do pensamento progressista presentes nas páginas do periódico. O especialista em análise econômica José Clemente de Oliveira (1962) chegou a afirmar que o capital estrangeiro, ao se infiltrar em setores estratégicos, subordinava a nação exigindo favores governamentais e isto ocasionou a ridícula posição do Brasil de eternos explorados. O autor que trabalhava no Banco Nacional de Desenvolvimento Econômico e Social (BNDES) defendeu projetos políticos que controlassem a remessa de lucros, poupanças em bancos estrangeiros, financiamentos e empréstimos, mostrando por meio de estatísticas econômicas as mais variadas formas da política imperialista.

O problema do capital estrangeiro também foi descrito pelo empresário e político do PTB José Ermírio de Morais. Por ser uma liderança empresarial defendeu que "[...] os industriais brasileiros em geral reconhecem a necessidade de investimentos estrangeiros na atual fase de desenvolvimento econômico" (MORAIS, 1962, p. 04), priorizando assim uma regulamentação que não destruísse a 
indústria nacional e que não afugentasse o financiamento externo.

A questão acima é uma das contradições do pensamento progressista, pois se o modo de produção capitalista está baseado na acumulação do capital por meio da exploração do trabalho, concentração de riqueza e monopolização comercial e industrial, é necessário ultrapassar as barreiras nacionais e impor uma política imperialista às nações que vivenciam estágios menos desenvolvidos deste sistema. Portanto, a partir da visão materialista da história, conclui-se que a crença de Morais (1962) em um ordenamento jurídico justo e capaz de contribuir para que um capital, verdadeiramente interessado em ter remuneração compensadora apoiasse o desenvolvimento nacional, não passa de uma concepção ilusória alimentada pela sociedade capitalista, pois o acúmulo de capital fortalece os monopólios e desarticula as concorrências.

O fato de o pensamento progressista ser de matriz reformista-liberal desmonta a ideia de que a emancipação nacional, defendida pela Frente Única, promoveria de forma plena transformações como a democratização do ensino, a erradicação do analfabetismo, a autonomia política e econômica, o desenvolvimento de uma cultura popular autêntica, a criação de um Estado democrático popular, a eliminação das diferenças sociais e a formação de um sistema agrícola e de um parque industrial que atendesse às exigências reais da população20. Pois, essa conjuntura contrapõe o sistema capitalista que, para expandir-se, age na contramão dessa realidade.

É preciso salientar que a UNE possuía certa clareza sobre a radicalização revolucionária, mas conferia notoriedade à luta anti-imperialista, num primeiro momento.

É possível inferir de nossa realidade que a contradição de classes torna-se mais e mais aguda, mas impossível não compreender que ela só poderá ser efetivamente superada, com a superação dos entraves espoliadores da dominação externa. É possível inferir que a revolução brasileira caminha para um termo radical, mas impossível não compreender que a primeira tarefa revolucionária é converter em internas as contradições brasileiras, suprimindo, inicialmente, a espoliação imperialista, sejam quais forem os métodos adotados para tanto (UNIÃO, 1962b, p. 29, grifo do autor).

\footnotetext{
20 Todas essas transformações foram atribuídas ao projeto de emancipação nacional e abordadas nas páginas da revista Movimento, por diferentes autores progressistas.
} 
Essa conversão, destacada pela UNE e defendida pelo PCB, representava a consolidação do capitalismo nacional em nosso país, tendo como objetivo final o socialismo. A luta deveria ser pacífica e por meios legais, unindo burguesia nacional, intelectuais, políticos progressistas, classe média, estudantes, operários e camponeses na tentativa de pressionar o congresso nacional para que aprovasse medidas desenvolvimentistas. Para Luís Carlos Prestes:

[...] os comunistas brasileiros lutam por um governo que assegure a plena emancipação econômica do país, a eliminação da estrutura agrária atrasada, a ampliação das liberdades democráticas e a melhoria das condições de vida das massas populares, bem como uma política externa independente (apud SILVA; CASTRO; GUIMARÃES, 1962, p. 5).

A importância dada pelo PCB ao desenvolvimento do capitalismo levou alguns grupos a criticar a falta de expressão revolucionária desse projeto emancipatório. O militante Maurício Grabois, do Partido Comunista do Brasil, por exemplo, alegou que a Declaração de Março de 1958 do PCB “[...] não exprime uma política justa, não corresponde aos interesses de classe do proletariado. No essencial, tal documento defende uma linha oportunista de direita" (GRABOIS, 2000, p. 13). Para esse jornalista, as novas diretrizes do PCB colocavam a problemática da revolução brasileira a partir do ponto de vista da burguesia, negando a luta revolucionária proletária e se adaptando ao capitalismo e isto contribuía para a propagação da ideologia burguesa junto às massas dificultando desta forma o avanço das lutas proletárias.

Na introdução da Crítica da filosofia do direito de Hegel, Karl Marx, ao comparar o contexto econômico e político da França e da Alemanha da primeira metade do século XIX, caracterizou o processo revolucionário concluindo que existiam dois tipos de revolução. A revolução parcial ou política, em que uma parte da sociedade civil se emancipa e alcança o domínio universal e a revolução radical, cujo propósito seria a emancipação humana universal sem interesses particulares de classe.

O sonho utópico da Alemanha não é a revolução radical, a emancipação humana universal, mas a revolução parcial, meramente política, a revolução que deixa de pé os pilares do edifício. Em que se baseia uma revolução parcial, meramente política? No fato de que uma parte da sociedade civil se emancipa e alcança o domínio universal; que uma determinada classe, a partir da sua situação particular, realiza a emancipação universal da sociedade. Tal classe liberta a sociedade inteira, mas apenas sob o pressuposto de que toda a sociedade se encontre na situação de sua classe, portanto, por exemplo, de que ela possua ou possa facilmente adquirir dinheiro e cultura (MARX, 2010, p. 154, grifo do autor). 
Verifica-se que a revolução parcial foi considerada utópica por Marx, porque não tinha como propósito a extinção das bases que originavam e estimulavam a divisão da sociedade em classes antagônicas, apesar das reformas provocadas. Ao contrário, a revolução radical, também denominada de emancipação humana universal, promoveria o aniquilamento dessas bases e consequentemente a supressão desse tipo de sociedade.

Com base nessa concepção, percebe-se que as forças progressistas brasileiras, entre elas a UNE, ao valorizar os interesses burgueses de fortalecimento do capitalismo nacional e se afastar dos verdadeiros grilhões da sociedade brasileira colaboraram na manutenção do capitalismo e do liberalismo, impossibilitando desta maneira a superação das contradições econômicas. Portanto, seu projeto revolucionário pode ser concebido como político, pois a situação particular que obstruía seus interesses eram o imperialismo e latifúndio; e, desta maneira, procuraram entusiasmar as massas e ser reconhecida como seu representante na luta democrática pelo desenvolvimento nacional, ou seja, a emancipação do povo brasileiro.

\section{Considerações Finais}

Os estudos históricos pela imprensa e fundamentados no materialismo histórico dialético partem do pressuposto de que é no seu processo de vida real, ou seja, na sua materialidade, que os homens transformam seus pensamentos, $\mathrm{e}$ "[...] tão logo seja apresentado esse processo ativo de vida, a história deixa de ser uma coleção de fatos mortos" (MARX; ENGELS, 2007, p. 94). Nesse sentido, este estudo procurou contextualizar historicamente o projeto de emancipação disseminado pelo periódico Movimento, levando em consideração as condições materiais da sociedade brasileira e o posicionamento da UNE, enquanto liderança política universitária e financiadora deste periódico estudantil.

As contradições do modo de produção capitalista no Brasil, durante a década de 1950 e 1960, contribuíram diretamente para o desenvolvimento do pensamento progressista. Destacam-se, por exemplo, a forte dominação do capitalismo externo no setor industrial nacional, principalmente o norte-americano, para sua sobrevivência; o monopólio da terra por latifundiários ligados aos interesses capitalistas internacionais; um Estado sem representatividade popular devido à alta taxa de analfabetos em idade eleitoral; uma política externa alinhada aos projetos do bloco capitalista liberal, liderado pelos EUA durante a Guerra Fria; a referência do PCB como liderança de esquerda e a defesa 
da revolução pacífica e a da aliança com a burguesia nacional; a propagação da ideologia nacionaldesenvolvimentista pelo ISEB; e, finalmente, a mobilização política ainda incipiente no caso dos operários e estritamente reduzida em relação aos camponeses.

A partir das condições materiais elencadas, as forças progressistas passaram a defender a tese de emancipação nacional, que naquela etapa histórica significava o desenvolvimento do capitalismo nacional. Enquanto integrante desse grupo, a UNE procurou utilizar vários mecanismos para difundir o pensamento progressista na busca de fortalecer o processo revolucionário democrático, nacional, desenvolvimentista, anti-imperialista e anti-latifúndiário. Dessa maneira, o periódico Movimento foi reestruturado para ser um canal desse projeto emancipatório e atuar revolucionariamente no movimento estudantil, segundo suas lideranças.

Nas páginas da revista, encontram-se denúncias ao domínio do capital estrangeiro e à estrutura agrária de raízes ainda coloniais, ou seja, dois elementos que impediam a evolução da economia brasileira, impossibilitando o desenvolvimento nacional. A questão do nacionalismo, no pensamento progressista, estava vinculada à defesa da autonomia econômica e produtiva do país. Em outras palavras, era preciso libertar-se do sistema vigente, do qual nossa produção voltava-se às demandas do comércio externo ditado pelas grandes potências capitalistas. O que estava em jogo, portanto, era um projeto político-econômico alinhado aos interesses de classes financeiramente e culturalmente privilegiadas, pois conforme já destacado os universitários, por exemplo, provinham majoritariamente da burguesia e da classe média.

Com base nos pressupostos de Marx e Engels, de que a revolução radical consiste na emancipação humana universal, conclui-se que o projeto de emancipação presente nas páginas do impresso estudantil Movimento possuía forte influência ideológica burguesa e restringiu-se ao campo político. A afirmativa procede da constatação de que, em vários artigos da revista, os autores centralizaram as causas das problemáticas brasileiras no imperialismo e na estrutura latifundiária e não em suas causas concretas, ou seja, a existência do modo de produção capitalista e suas contradições, o que colaborou para a manutenção dos pilares desse sistema. Além disso, é fundamental destacar que o comportamento desses sujeitos universitários, alinhado ao pensamento progressista, não poderia ser outro, devido as suas origens elitistas e por consequência um conhecimento limitado das reais problemáticas do Brasil. 


\section{Referências}

ABEND, A. O grande país dos analfabetos. Movimento, Rio de Janeiro: Universitária, n. 2, maio, p. 0507, 1962.

AÇÃO POPULAR. Documento Base, p. 6919-6934, 1963.

ALVES, M. Frente única e a burguesia nacional. Movimento, Rio de Janeiro: Universitária, n. 9, p. 2931, mar. 1963.

BRANDT, V. C. Depoimento. Movimento, Rio de Janeiro: Universitária, n. 5, p. 26-27, set. 1962.

CASTRO, P. Panamericanismo: essência e futuro. Movimento, Rio de Janeiro: Universitária, n. 1, p. 0405, mar. 1962.

CUBA NÃO ESTÁ SÓ. Movimento, Rio de Janeiro: Universitária, n. 10, p. 16-19, abr. 1963.

DERENGOSQUI, P. Roteiro explicativo do socialismo tropical. Movimento, Rio de Janeiro: Universitária, n. 7, p. 16-24, nov. 1962.

EDITORIAL. Movimento, Rio de Janeiro: Universitária, n. 1, p. 03, mar. 1962.

ENGELS, F. Do Socialismo Utópico ao Socialismo Científico. 1880. Disponível em: <https://www.marxists.org/portugues/marx/1880/socialismo/>. Acesso em: 17 dez. 2016.

Princípios básicos do comunismo. 1847. Disponível em: <https://www.marxists.org/portugues/marx/1847/11/principios.htm>. Acesso em: 16 dez. 2016.

FORACCHI, M. M. O estudante e a transformação da sociedade brasileira. São Paulo: Nacional, 1965.

GRABOIS, M. Duas concepções, duas orientações políticas. 1960. In: PC do B. Em defesa dos trabalhadores e do povo brasileiro: documentos do PC do Brasil de 1960 a 2000. São Paulo: Anita Garibaldi, 2000. p. 13-22.

MARINI FILHO, H. Cuba: território livre da América. Movimento, Rio de Janeiro: Universitária, n. 1, p. 06-09, mar. 1962.

MARX, K. A Questão Judaica. $1843 . \quad$ Disponível em: <http://www.lusosofia.net/textos/marx_questao_judaica.pdf >. Acesso em: 21 jul. 2017.

. Crítica da filosofia do direito de Hegel. Tradução Rubens Enderle e Leonardo de Deus. 2. ed. rev. São Paulo: Boitempo, 2010.

MARX, K.; ENGELS, F. A ideologia alemã. Tradução de Rubens Enderle, Nélio Schneider e Luciano Cavini Martorano. São Paulo: Boitempo, 2007.

. Manifesto do Partido Comunista. Tradução de Sergio Tellaroli. São Paulo, Penguin Classics/ Companhia das Letras, 2012.

MORAIS, J. E. Regulamentação de lucros. Movimento, Rio de Janeiro: Universitária, n. 2, p. 04, maio 1962.

OLIVEIRA, J. C. Capital estrangeiro. Movimento, Rio de Janeiro: Universitária, n. 2, p. 13-15, maio 1962.

OLIVEIRA, R. S. A relação entre a História e a Imprensa, breve história da imprensa e as origens da imprensa no Brasil (1808-1930). Historiæ, Rio Grande, v. 2, n. 3, p. 125-142, set./dez. 2011. 
PARTIDO COMUNISTA BRASILEIRO. Resolução de 1958 do PCB. 1958. In: PC do B. Em defesa dos trabalhadores e do povo brasileiro: documentos do PC do Brasil de 1960 a 2000. São Paulo: Anita Garibaldi, 2000. p. 515-532.

POERNER, A. J. O poder jovem. 2. ed. Rio de Janeiro: Civilização Brasileira, 1979.

PRADO Jr., C. História Econômica do Brasil. 26. ed. São Paulo: Brasiliense, 1981.

PRESTES, L. C. Suplemento de Novos Rumos de 11 a 17/08. In: SILVA, L. L.; CASTRO, P. F.; GUIMARÃES, C. Hora e vez da boa escolha. Movimento, Rio de Janeiro: Universitária, n. 6, p. 03-07, out. 1962.

SAMPAIO, H. Evolução do ensino superior brasileiro (1808-1990). Documento de Trabalho 8/91. Núcleo de Pesquisa sobre Ensino Superior da Universidade de São Paulo, 1991. Disponível em: <http://nupps.usp.br/downloads/docs/dt9108.pdf.> Acesso em: 26 jul. 2017.

SANTOS, W. G. Fatos sobre limitação fundamental da burguesia. Movimento, Rio de Janeiro: Universitária, n. 7, p. 35-38, nov. 1962.

SODRÉ, N. W. Introdução à Revolução Brasileira. Rio de Janeiro: Civilização Brasileira, 2. ed. Rio de Janeiro, 1963.

SOUZA, L. A. G. O neutralismo no processo mundial de socialização. Movimento, Rio de Janeiro: Universitária, n. 8, p. 17-24, fev. 1963.

TOLEDO, C. A. A.; SKALINSKI Jr., O. A imprensa periódica como fonte para a História da Educação: teoria e método. Revista HISTEDBR On-line, Campinas, n. 48, p. 255-268, 2012.

TOLEDO, C. N. de. ISEB: fábrica de ideologias. Campinas: UNICAMP, 1997.

UNIÃO NACIONAL DOS ESTUDANTES. II seminário nacional de reforma universitária. Curitiba. 1962a. $1962 b$.

. Luta pela emancipação nacional. Movimento, Rio de Janeiro: Universitária, n. 4, p. 29-31, jul. 